\title{
Dialysis Access Complication
}

National Cancer Institute

\section{Source}

National Cancer Institute. Dialysis Access Complication. NCI Thesaurus. Code C116081.

Any issue that arises as a consequence of a problem with a patient's dialysis access. 